\title{
LAS CONTROVERSIAS CONSTITUCIONALES Y LOS ÓRGANOS AUTÓNOMOS
}

\author{
THE CONSTITUTIONAL CONTROVERSIES \\ AND THE INDEPENDENT CONSTITUTIONAL ENTITIES
}

\author{
JOSÉ OVALLE FAVELA*
}

RESUMEN: Se analiza la evolución que ha tenido la jurisprudencia de la Suprema Corte de Justicia de la Nación sobre la legitimación en la causa de los órganos constitucionales autónomos para promover controversias constitucionales; es decir, los procesos que pueden promover entidades, poderes y órganos públicos ante la Suprema Corte, con la finalidad de que ésta determine si los actos o disposiciones de otras entidades, poderes y órganos públicos invaden las atribuciones que la Constitución Política confiere a los primeros. Se estudia el origen y desarrollo de tales controversias en el derecho mexicano, su clasificación y su objeto, la doctrina y la jurisprudencia sobre la legitimación tanto procesal como en la causa.

Palabras clave: controversias constitucionales, Suprema Corte de Justicia de la Nación, órganos constitucionales autónomos, legitimación en la causa, legitimación procesal, jurisprudencia.

* Investigador en el Instituto de Investigaciones Jurídicas y profesor de la Facultad de Derecho, ambos de la UNAM; investigador nacional nivel III. Este artículo se publica con autorización del Banco de México.
ABSTRACT: Analyzes the evolution of the jurisprudence of the Supreme Court of Justice of the Nation regarding the standing that independent constitutional entities have to file "constitutional controversies" (controversias constitucionales), the is, the procedures that can be filed by the branches of government, states and public entities before the Supreme Court, with the purpose of determining whether the acts or legislation passed by other states and public entities invade the authority that the Political Constitution confers to them. This article also summarizes the origin and development of those controversies in mexican law, its classification and its object, the doctrine and the jurisprudence concerning the standing to file them.

Descriptors: constitutional controversies, Supreme Court of Justice, independent constitutional entities, standing, jurisprudence 


\section{PLANTEAMiENTO}

El objeto de este trabajo consiste en analizar la posibilidad jurídica de que, a través de la interpretación constitucional, se reconozca a los órganos autónomos legitimación activa en la causa para promover controversias constitucionales.

Para tal fin se estudian los orígenes y el desarrollo de las controversias constitucionales, se propone una clasificación de tales controversias, se examina la doctrina y la jurisprudencia sobre la legitimación tanto procesal como en la causa, así como sobre los órganos constitucionales autónomos y su posible legitimación.

En el derecho mexicano se denominan controversias constitucionales a los procesos que pueden promover entidades, poderes y órganos públicos ante la Suprema Corte de Justicia de la Nación, con la finalidad de que ésta determine si los actos o disposiciones generales de otras entidades, poderes y órganos públicos invaden las atribuciones que la Constitución Política confiere a los primeros.

Estas controversias se encuentran previstas en el artículo 105, fracción I, de la Constitución Política de 1917. Sin embargo, para entender su significado actual conviene hacer una breve relación de sus antecedentes.

\section{ORÍGENES Y EVOLUCIÓN}

Desde la Constitución Federal de 1824 se atribuyó a la Suprema Corte de Justicia de la Nación la facultad de conocer de las diferencias que pudieran existir entre dos Estados de la Federación, "siempre que las reduzcan a un juicio verdaderamente contencioso en que deba recaer formal sentencia" (artículo 137, fracción I). ${ }^{1}$

En la Constitución política de 1857 también se facultó a la Suprema Corte de Justicia para conocer de "las controversias que se susciten de un Estado con otro" (artículo 98). ${ }^{2}$ Este precepto sólo fue motivo de dudas

1 Tena Ramírez, Felipe, Leyes fundamentales de México: 1808-1999, México, Porúa, 1999, p. 188.

2 Ibidem, p. 623. 
y aclaraciones en el Congreso Constituyente de 1856-1857, pero no de debate, por lo que fue aprobado por unanimidad de 79 votos. ${ }^{3}$

Pero la regulación más amplia de las controversias constitucionales se inicia en la Constitución Política de 1917. Originalmente esta materia era objeto del artículo 104 del proyecto de Constitución presentado por Venustiano Carranza, en su carácter de Primer Jefe del Ejército Constitucionalista Encargado del Despacho del Poder Ejecutivo. El texto de este artículo era el siguiente:

Artículo 104. Corresponde sólo a la Suprema Corte de Justicia de la Nación, conocer de las controversias que se susciten entre dos o más Estados, entre los poderes de un mismo Estado con motivo de sus respectivas atribuciones o sobre la constitucionalidad de sus actos, y de los conflictos entre la Federación y uno o más Estados, así como aquellas en que la Federación fuere parte. ${ }^{4}$

En el dictamen presentado el 20 de enero de 1917 por la Segunda Comisión de Constitución se suprimió la expresión "con motivo de sus respectivas atribuciones", por considerar que el conocimiento de los conflictos sobre atribuciones de los Estados ya había sido encargado al Senado en el artículo 76, fracción VIII, de la propia Constitución. ${ }^{5}$ En el mismo dictamen se propuso cambiar el número del artículo, que pasaría a ser el 105.

Una de las cuestiones que más se debatieron en el Congreso Constituyente de 1916-1917 fue la necesidad de distinguir entre la competencia que el artículo 76, fracción VIII, atribuía al Senado para resolver las cuestiones políticas que surgieran entre los poderes de un Estado, de la competencia que el artículo 105 otorgaba a la Suprema Corte de Justicia de la Nación

3 Cfr. Zarco, Francisco, Crónica del Congreso Extraordinario Constituyente (18561857), México, El Colegio de México, 1957, p. 724.

4 Tena Ramírez, op. cit., p. 793.

5 De acuerdo con el texto original del precepto mencionado, era facultad exclusiva del Senado: "Resolver las cuestiones políticas que surjan entre los poderes de un Estado, cuando alguno de ellos ocurra con ese fin al Senado, o cuando, con motivo de dichas cuestiones, se haya interrumpido el orden constitucional, mediante un conflicto de armas. En este caso el Senado dictará su resolución sujetándose a la Constitución General de la República y a la del Estado". Actualmente la fracción transcrita es la VI del citado artículo 76. La Ley reglamentaria de dicha fracción fue publicada en el Diario Oficial de la Federación del 31 de agosto de 2007. Cfr. Sánchez Gil, Rubén, "Resolución de «cuestiones políticas»: controversia constitucional y procedimiento senatorial", en Revista Iberoamericana de Derecho Procesal Constitucional, México, núm. 8, julio-septiembre de 2007, pp. 283-335. 
para conocer de las controversias que se suscitaran entre dos o más Estados, o entre los poderes de un mismo Estado sobre la constitucionalidad de sus actos.

Sobre este tema, el diputado Hilario Medina afirmó que el artículo 105 atribuía a de la Suprema Corte de Justicia de la Nación la competencia para conocer y resolver los conflictos que existieran entre dos poderes de un mismo Estado sobre la constitucionalidad de los actos, es decir, facultaba a la Suprema Corte para conocer de la materia estrictamente constitucional; y que la fracción VIII del artículo 76, dejaba al Senado el conocimiento de la materias política. El diputado Medina dio lectura a la fracción VIII del artículo 76, cuyo texto se reproduce en la nota 5 de este trabajo, para establecer la siguiente distinción:

La sola lectura de esta fracción indica la diferencia entre una cuestión política, en la cual uno de los poderes (de un Estado) ocurre al Senado cuando ha mediado conflicto de armas, y una cuestión netamente constitucional en la cual no hay contienda armada, ni elementos populares que intervengan rompiendo el orden constitucional, de manera que la cuestión meramente constitucional la puede conocer la Corte, porque ella es la que debe decir la última palabra en cuestiones constitucionales, y las cuestiones políticas en las que surjan conflicto de armas son resueltas por el Senado dando una solución oportuna y designando alguna persona que apacigüe a los contendientes, dando la razón al que la tenga. Esto explica que yo, que sostuve la tesis de que las cuestiones políticas corresponden al Senado, he aceptado que las cuestiones meramente constitucionales corresponden a la Corte, porque así es su papel y tales son sus atribuciones. ${ }^{6}$

Sin embargo, como algunos diputados constituyentes manifestaron sus dudas sobre las diferencias entre las cuestiones políticas y las controversias constitucionales, el diputado González M. propuso que se sustituyera la conjunción disyuntiva "o" por la copulativa " $y$ " en la fracción VIII del artículo 76, a fin de que el Senado resolviera las cuestiones políticas cuando, con motivo de ellas, se haya interrumpido el orden constitucional, mediante un conflicto de armas. No obstante, este cambio no fue sometido a la votación del Congreso, por lo que la fracción VIII del artículo 76 quedó tal como

6 Diario de los debates del Congreso Constituyente, México, Imprenta de la Cámara de Diputados, 1922, t. II, p. 563. 
había sido aprobada por el Congreso en su sesión del día 16 de enero de 1917, cuyo texto se reproduce en la nota 5.

El artículo 105, tal como fue aprobado en la misma sesión del 22 de enero de 1917, dispuso lo siguiente:

Artículo 105. Corresponde sólo a la Suprema Corte de Justicia de la Nación, conocer de las controversias que se susciten entre dos o más Estados, entre los poderes de un mismo Estado sobre la constitucionalidad de sus actos, y de los conflictos entre la Federación y uno o más Estados, así como de aquéllos en que la Federación fuese parte. ${ }^{7}$

Este precepto atribuía a la Suprema Corte de Justicia el conocimiento y la resolución de las controversias que se suscitaran entre: $a$ ) dos o más estados; $b$ ) los poderes de un mismo estado, y c) la Federación y uno o más estados. Aunque el artículo 105 parecía referir la expresión "sobre la constitucionalidad de sus actos" sólo a las controversias indicadas en el inciso b, es claro que tal expresión se debía aplicar a las demás controversias, pues el objeto de todas ellas era que la Suprema Corte de Justicia determinara si los actos o disposiciones generales impugnados se apegaban a la Constitución Política.

Por último, es evidente que los conflictos en los que la Federación sea parte no se ubican dentro del concepto de controversias constitucionales, pues no se suscitan entre entidades, poderes y órganos públicos, ni se refieren necesariamente a la constitucionalidad de determinados actos o disposiciones generales, sino que se trata de conflictos que se debían y se deben sustanciar normalmente a través de juicios civiles federales. ${ }^{8}$

\section{LA REFORMA CONSTITUCIONAL DE 1994}

Sin duda, en el decreto de reformas y ediciones a diversos artículos de la Constitución Política, entre ellos el artículo 105, publicado en el Diario Oficial de la Federación del 31 de diciembre de 1994, tuvo una especial relevancia en la regulación de las controversias constitucionales. Este

7 Ibidem, p. XXIII (texto original de la Constitución Política de 1917, que aparece al final de la obra).

8 Cfr. Fix-Zamudio, Héctor, Estudio de la defensa de la Constitución en el ordenamiento mexicano, México, Porrúa-UNAM, 2005, p. 212. 
decreto amplió las entidades, poderes y órganos públicos que pueden ser sujetos de las controversias constitucionales, al incluir de manera expresa a los municipios y al Distrito Federal, y señaló con mayor precisión los poderes y los órganos públicos sujetos a las controversias constitucionales.

En la iniciativa que el presidente de la República envió el 5 de diciembre de 1994 al Senado para proponer las reformas y adiciones mencionadas, se destacó el papel esencial de la Suprema Corte de Justicia de la Nación en la solución de las controversias constitucionales. Entre otras cosas, el presidente manifestó:

Por eso, una Suprema Corte de Justicia libre, autónoma, fortalecida y de excelencia, es esencial para la cabal vigencia de la Constitución y el estado de derecho que ella consagra. En la Suprema Corte de Justicia la voluntad popular ha depositado la función fundamental de mantener el equilibrio entre los Poderes de la Unión, dirimiendo las controversias que pudieran suscitarse entre el Ejecutivo y el Legislativo. Así también, la Suprema Corte es depositaria del supremo mandato de velar por la unión de la República dirimiendo las controversias entre Estados, Municipios, el Distrito Federal y la Federación.

En la iniciativa el presidente de la República propuso:

...la modificación del artículo 105 a fin de prever en su fracción I las bases generales de un nuevo modelo para la solución de las controversias sobre la constitucionalidad de los actos que surjan entre la Federación y un Estado o el Distrito Federal, la Federación y un Municipio, el Poder Ejecutivo y el Congreso de la Unión, aquél y cualquiera de las Cámaras de éste, o, en su caso, la Comisión Permanente, sea como órganos federales o del Distrito Federal, dos Estados, un Estado y el Distrito Federal, el Distrito Federal y un Municipio; dos Municipios de diversos Estados, dos Poderes de un mismo Estado; un Estado y uno de sus Municipios; dos órganos del Distrito Federal o dos Municipios de un mismo Estado. ${ }^{9}$

El texto aprobado por el Congreso de la Unión y por la mayoría de las legislaturas de los Estados, es el siguiente:

Artículo 105. La Suprema Corte de Justicia de la Nación conocerá, en los términos que señale la ley reglamentaria, de los asuntos siguientes:

9 Cfr. Acuña Méndez, Francisco, La controversia constitucional en México, México, Porrúa, 2004, pp. 92 y 93. 
I. De las controversias constitucionales que, con excepción de las que se refieran a la materia electoral, se susciten entre:

a) La Federación y un Estado o el Distrito Federal;

b) La Federación y un Municipio;

c) El Poder Ejecutivo y el Congreso de la Unión; aquél y cualquiera de las Cámaras de éste o, en su caso, la Comisión Permanente, sean como órganos federales o del Distrito Federal;

d) Un Estado y otro;

e) Un Estado y el Distrito Federal;

f) El Distrito Federal y un Municipio;

g) Dos Municipios de diversos Estados;

h) Dos Poderes de un mismo Estado, sobre la constitucionalidad de sus actos o disposiciones generales;

i) Un Estado y uno de sus Municipios, sobre la constitucionalidad de sus actos o disposiciones generales;

j) Un Estado y un Municipio de otro Estado, sobre la constitucionalidad de sus actos o disposiciones generales; y

k) Dos órganos de gobierno del Distrito Federal, sobre la constitucionalidad de sus actos o disposiciones generales.

Siempre que las controversias versen sobre disposiciones generales de los Estados o de los Municipios impugnadas por la Federación, de los Municipios impugnadas por los Estados, o en los casos a que se refieren los incisos c, h y k anteriores, y la resolución de la Suprema Corte de Justicia las declare inválidas, dicha resolución tendrá efectos generales cuando hubiera sido aprobada por una mayoría de por lo menos ocho votos.

En los demás casos, las resoluciones de la Suprema Corte de Justicia tendrán efectos únicamente respecto de las partes en la controversia.

De acuerdo con lo que comentamos anteriormente, en el texto reformado del artículo 105, fracción I, de la Constitución Política, se advierte que, por una parte, se reconocen como nuevas entidades con legitimación para promover las controversias constitucionales, al Distrito Federal y a los municipios; y por la otra, se precisan los órganos de gobierno dentro del poder legislativo federal, que pueden promover las controversias constitucionales, como es el caso de las cámaras del Congreso de la Unión. Es conveniente aclarar que antes de la reforma constitucional de 1994 la Suprema Corte había reconocido legitimación a los municipios. ${ }^{10}$

10 Véase la tesis de jurisprudencia P./J. 29/2000, “CONTROVERSIA CONSTITUCIONAL. LOS MUNICIPIOS TIENEN LEGITIMACIÓN PARA PROMOVERLA EN LOS TÉRMINOS DEL ARTÍCU- 
La fracción I del artículo 105 constitucional fue reformada en su primer párrafo por el decreto publicado en el Diario Oficial de la Federación del 8 de diciembre de 2006, para aclarar que se exceptúan, además de las controversias que se refieran a la materia electoral, también las que conciernan "a lo establecido en el artículo 46 de esta Constitución”. De este modo, el primer párrafo quedó en los siguientes términos: "I. De las controversias constitucionales que, con excepción de las que se refieran a la materia electoral y a lo establecido en el artículo 46 de esta Constitución, se susciten entre...".

De acuerdo con esta reforma, se exceptúa de la competencia de la Suprema Corte el conocimiento de aquellas controversias sobre límites territoriales entre entidades federativas, cuando cualquiera de éstas haya solicitado la intervención del Senado, conforme a lo que dispone el artículo 76, fracción XI, de la Constitución Política.

\section{UNA PROPUESTA DE CLASIFICACIÓN}

Las controversias constitucionales previstas en el artículo 105, fracción I, de la Constitución Política, se pueden clasificar en internas, cuando surgen entre los diversos poderes de una misma entidad (Federación, estado o Distrito Federal), y externas, cuando se establecen entre las propias entidades entre sí (Federación, estado, Distrito Federal y municipios).

Las controversias constitucionales internas se pueden presentar, conforme a lo que dispone el artículo 105, fracción I, de la Constitución Política, entre los órganos siguientes:

a) el Poder Ejecutivo Federal y el Congreso de la Unión, las cámaras de éste o la Comisión Permanente;

b) dos poderes de un mismo Estado;

c) dos órganos de gobierno del Distrito Federal.

Las controversias constitucionales externas pueden subdividirse, a su vez, en horizontales, cuando se manifiestan entre entidades del mismo nivel de 
descentralización política, y verticales, cuando las entidades en conflicto tienen diferente nivel.

Las controversias externas horizontales que enuncia la fracción I del artículo 105, son las que pueden surgir entre:

a) dos estados;

b) un estado y el Distrito Federal, y

c) dos municipios de diversos Estados (ya que los conflictos entre municipios del mismo estado normalmente deben ser resueltos por el Poder Judicial del propio estado).

Las controversias externas verticales son las que se pueden presentar entre:

a) la Federación y un estado o el Distrito Federal;

b) la Federación y un municipio, y

c) un estado o el Distrito Federal y un municipio. ${ }^{11}$

\section{EL OBJETO DE LAS CONTROVERSIAS CONSTITUCIONALES}

Al inicio de este estudio señalamos que la finalidad de los procesos sobre controversias constitucionales consiste en que la Suprema Corte de Justicia determine si los actos o disposiciones generales impugnados infringen los límites que la Constitución Política establece para el ejercicio de las atribuciones de las entidades, poderes y órganos públicos. Esta finalidad se advierte desde la lectura de la fracción I del artículo 105 constitucional, en cuyos incisos h, i, j y k, se señala que las controversias constitucionales versan sobre la constitucionalidad de los actos o de las disposiciones generales de las entidades, poderes y órganos públicos demandados.

En este sentido, la Suprema Corte de Justicia ha sostenido que las controversias constitucionales, como medios de control de la regularidad constitucional, tienen como finalidad primordial "la protección del ámbito de atribuciones que la misma Ley Suprema prevé para los órganos originarios del Estado, es decir, aquellos que derivan del sistema federal y del principio de división de poderes a que se refieren los artículos 40, 41 y 49, en relación

11 Cfr. Ovalle Favela, José, Teoría general del proceso, 6a. ed., México, Oxford University Press, 2005, p. 81. 
con el 115, 116 y 122, de la propia Constitución", ${ }^{12}$ así como la de que la actuación de las autoridades se ajuste a lo establecido en la Constitución; ${ }^{13}$ que "esta garantía constitucional tiene como finalidad preservar el sistema de distribución de competencias entre los distintos niveles de gobierno y entre los distintos poderes..."; ${ }^{14} \mathrm{y}$ en fin, que las controversias constitucionales "tienen como finalidad fundamental el establecimiento de un medio de defensa judicial en el que los poderes o entidades que se consideren afectados por actos realizados por otro poder o entidad puedan defender ante la Suprema Corte de Justicia de la Nación sus respectivas esferas de atribuciones...". ${ }^{15}$

\section{LA LEGITIMACIÓN}

En la doctrina procesal se distingue entre la legitimación en la causa (ad causam) y la legitimación procesal (ad processum). En este sentido, Chiovenda entendía a la legitimación en la causa como "la identidad de la persona del actor con la persona a la cual la ley concede la acción (legitimación activa) y la identidad de la persona del demandado con la persona contra la cual es concedida la acción (legitimación pasiva)" ${ }^{16}$ En el mismo sentido, Calamandrei afirmaba que, a fin de que el juez provea en sentido

12 Tesis aislada P. LXXII/98, “CONTROVERSIA CONSTITUCIONAL. LA TUTELA JURÍDICA DE ESTA ACCIÓN ES LA PROTECCIÓN DEL ÁMBITO DE ATRIBUCIONES QUE LA LEY SUPREMA PREVÉ PARA LOS ÓRGANOS ORIGINARIOS DEL ESTADO", Semanario Judicial de la Federación y su Gaceta, t. VIII, diciembre de 1998, p. 789, registro 195025.

13 Tesis de jurisprudencia P./J. 98/99, "CONTROVERSIA CONSTITUCIONAL. EL CONTROL DE LA REGULARIDAD CONSTITUCIONAL A CARGO DE LA SUPREMA CORTE DE JUSTICIA DE LA NACIÓN, AUTORIZA EL EXAMEN DE TODO TIPO DE VIOLACIONES A LA CONSTITUCIÓN FEDERAL", Semanario Judicial de la Federación y su Gaceta, Novena Época, t. X, septiembre de 1999, p. 703, registro: 193,259.

14 Tesis aislada 2a. LXXXVIII/98, "CONTROVERSIAS CONSTITUCIONALES. UN ORGANISMO PÚBLICO DESCENTRALIZADO ESTATAL CARECE DE LEGITIMACIÓN ACTIVA EN LA CAUSA", Semanario Judicial de la Federación y su Gaceta, Novena Época, t. VII, junio de 1998, p. 421, registro: 903,862.

15 Tesis de jurisprudencia P./J. 83/2000, "Cámaras de Diputados y de Senadores. Están legitimadas aisladamente para plantear la defensa de las atribuciones que el artículo 73 de la Constitución Política de los Estados Unidos Mexicanos establece a favor del Congreso de la Unión”, Semanario Judicial de la Federación y su Gaceta, Novena Época, t. XII, agosto de 2000, p. 962, registro: 191,295.

16 Chiovenda, Giuseppe, Principios de derecho procesal civil, trad. de José Casais y Santaló, Madrid, Reus, 1977, t. II, p. 16. 
favorable al solicitante, no basta que la demanda le sea propuesta por una persona cualquiera, sino que es necesario que le sea presentada precisamente por aquella persona que la ley considera particularmente idónea para estimular en el caso concreto la función jurisdiccional. ${ }^{17}$

Para la Suprema Corte de Justicia la legitimación de la causa implica tener la titularidad del derecho cuestionado en el juicio. ${ }^{18}$

En cambio, la legitimación procesal consiste en la aptitud o idoneidad para actuar en un proceso en el ejercicio de un derecho propio o en representación de otro. ${ }^{19}$ La Suprema Corte de Justicia considera que por legitimación procesal activa se entiende la potestad legal para acudir al órgano jurisdiccional con la petición de que se inicie la tramitación del juicio o de una instancia. ${ }^{20}$

Para subrayar las diferencias que existen entre ambos conceptos, la propia Suprema Corte ha afirmado que:

la legitimación en la causa es la vinculación que existe entre quien invoca un derecho sustantivo y el derecho mismo que hace valer ante los órganos jurisdiccionales, cuando ese derecho es violado o desconocido; mientras que la legitimación en el proceso es un presupuesto procesal que se refiere a la capacidad de las partes para ejecutar válidamente actos procesales y, por tanto, es condición para la validez formal del juicio. ${ }^{21}$

Conviene hacer algunas precisiones sobre el concepto de legitimación en la causa y su tratamiento y análisis en el proceso. Nos parecen acertadas las definiciones de Chiovenda y Calamandrei, pero expresamos nuestras dudas acerca de que tal legitimación solo la tenga quien es titular del derecho cuestionado en el juicio.

17 Calamandrei, Piero, Instituciones de derecho procesal civil según el nuevo Código, trad. Santiago Sentís Melenmdo, Buenos Aires, EJEA, 1973, t. I, p. 262.

18 Tesis de jurisprudencia 2a./J. 75/97, "LEGITIMACIÓN PROCESAL ACTIVA. CONCEPTO”, Semanario Judicial de la Federación y su Gaceta, Novena Época, t. VII, enero de 1998, p. 351, registro: 196,956.

19 Cfr. Couture, Eduardo J., Vocabulario jurídico, Buenos Aires, Depalma, 1976, p. 380.

20 Tesis de jurisprudencia cit. nota 17.

21 Tesis de jurisprudencia P./J. 91/99, “CONTROVERSIA CONSTITUCIONAL. LA FALTA DE LEGITIMACIÓN PROCESAL DE LOS SERVIDORES PÚBLICOS PROMOVENTES DEL JUICIO NO LLEVA A SOBRESEER SINO A DECLARAR QUE CARECEN DE ELLA", Semanario Judicial de la Federación y su Gaceta, Novena Época, t. X, septiembre de 1999, p. 706, registro 193267. 
Vamos a mencionar dos ejemplos en materia procesal civil, en los que el ordenamiento jurídico reconoce legitimación en la causa a personas que no son "titulares del derecho cuestionado en juicio". Así, para demandar la rectificación de un acta del estado civil, el artículo 136 del Código Civil para el Distrito Federal dispone que tienen legitimación (en la causa), además de la persona de cuyo estado civil se trate, las siguientes: $a$ ) "las que se mencionan en el acta como relacionadas con el estado civil de alguno" (los padres, los abuelos, etcétera): $b$ ) los herederos de la persona de cuyo estado civil se trate y los herederos de las personas señaladas en el inciso anterior, y c) "los que, según los artículos 348, 349 y 350, pueden continuar o iniciar la acción de que en ellos se trata" (acción "de filiación”).

El artículo 315 del mismo Código Civil reconoce legitimación para demandar el pago de alimentos, además del acreedor alimentario, a las siguientes personas: $a$ ) quien ejerza la patria potestad o tenga la guarda y custodia del menor; $b$ ) el tutor; $c$ ) los hermanos y demás parientes colaterales dentro del cuarto grado; $d$ ) la persona que tenga bajo su cuidado al acreedor alimentario, y e) el Ministerio Público.

En la mayor parte de los ejemplos citados, la legitimación activa en la causa se otorga a personas que no son titulares del derecho cuestionado en el proceso, pero que sí tienen una vinculación con el objeto de éste. Por esta razón, estimamos que se puede definir la legitimación en la causa como la autorización que el ordenamiento jurídico otorga a una persona para ser parte en un proceso, por su vinculación específica con el litigio objeto del mismo, ya sea como parte actora (legitimación activa) o como demandada (legitimación pasiva). ${ }^{22}$

La legitimación procesal es una condición intrínseca de la persona, que consiste en su aptitud para comparecer en el proceso en ejercicio de un derecho propio o en representación de otra persona. La legitimación en la causa es una condición extrínseca de la persona, que no depende su capacidad procesal, sino de su vinculación con el litigio objeto del proceso.

Por otro lado, si se exige que desde que se presente la demanda el actor acredite tanto su legitimación procesal como su legitimación en la causa, y que esta última no podrá variarse en el curso del proceso, ${ }^{23}$ no existe ninguna razón por la que la legitimación en la causa se tenga que analizar y

22 Ovalle Favela, op. cit., pp. 272 y 273.

23 Cfr. tesis aislada I.6o.C.142 C, "Legitimación en la causa", Semanario Judicial de la Federación y su Gaceta, Novena Época, t. VII, junio de 1998, p. 667, registro 196138. 
resolver hasta que se dicte la sentencia definitiva, si los documentos para acreditar esa legitimación tuvieron que se presentados con la demanda. La legitimación en la causa, exactamente igual que la legitimación procesal, es un presupuesto procesal que tiene que acreditarse desde el inicio de la relación jurídica procesal y el juzgador tiene el deber de analizarlo de oficio, por lo que si con los documentos aportados con la demanda se puede determinar que la parte actora carece de legitimación en la causa, debe resolverlo así desde entonces, por lo que no tiene sentido alguno seguir todos los trámites del proceso para que al final, al momento de dictar la sentencia definitiva, se llegue a la conclusión de que el actor no tenía legitimación en la causa. ${ }^{24}$

\section{LA LEGITIMACIÓN ACTIVA EN LA CAUSA}

Se puede afirmar, como regla general, que tienen legitimación activa en la causa las entidades, poderes y órganos de gobierno mencionados en el artículo 105, fracción I, de la Constitución Política. En un principio, tanto la doctrina como la jurisprudencia consideraron que sólo tenían legitimación en la causa para promover controversias constitucionales las entidades, poderes y órganos de gobierno enumerados expresamente en la fracción I del artículo 105 de la Constitución Política, por lo que estimaron que tal enumeración tenía carácter limitativo. En este sentido, Elisur Arteaga expresaba lo siguiente:

Sólo pueden ser parte en una controversia aquellos a quienes la constitución autoriza expresamente. Únicamente pueden figurar como partes, ya sea como actoras o demandadas, ciertas autoridades; ella sólo se puede dar entre: la federación, los estados, el Distrito Federal y los municipios; eso es lo que hace que opere la competencia exclusiva del pleno de la corte; esa debe ser la regla general, válida en todo caso, salvo que se trate de un acto que afecte

${ }^{24}$ Sostienen que la legitimación en la causa sólo puede analizarse en la sentencia definitiva en materia civil, las tesis de jurisprudencia: I.11o.C. J/12, "LEGITIMACIÓN ACTIVA EN LA CAUSA. ES UNA CONDICIÓN NECESARIA PARA LA PROCEDENCIA DE LA ACCIÓN Y SÓLO PUEDE ANALIZARSE DE OFICIO POR EL JUZGADOR AL MOMENTO DE DICTAR SENTENCIA", Semanario Judicial de la Federación y su Gaceta, Novena Época, t. XXVII, abril de 2008, p. 2066, registro 169857, y VI.3o.C. J/67, "LEGITIMACIÓN EN LA CAUSA. SóLO PUEDE ESTUDIARSE EN LA SENTENCIA DEFINITIVA", Semanario Judicial de la Federación y su Gaceta, Novena Época, t. XXVIII, Julio de 2008, p. 1600, registro 169271. 
directa, expresa y limitadamente a un poder u órgano de autoridad determinado y exista norma expresa que así lo permita como lo hacen los incisos (c), (h) y (k) de la fracción I del artículo 105.25

La Suprema Corte de Justicia de la Nación originalmente sostuvo también que la fracción I del artículo 105 de la Constitución Política establecía:

limitativamente los órganos, poderes o entidades legitimadas para promover la acción de controversia constitucional, de suerte que al no estar comprendido un organismo público descentralizado estatal dentro de la enumeración efectuada por el precepto de la ley fundamental citado, debe concluirse que carece de la legitimación activa para promover este mecanismo de control constitucional. ${ }^{26}$

Sin embargo, la propia Suprema Corte de Justicia de la Nación empezó a cambiar su criterio, al sostener primero que si bien es cierto que los órganos derivados (es decir, aquellos que no tienen delimitada su esfera de competencia en la Constitución Federal sino en una ley), no podían tener legitimación activa en la causa, pues ésta corresponde a los órganos primarios (que son aquellos que se tienen establecida su competencia en la Constitución y son enumerados por la fracción I del artículo 105 constitucional), ${ }^{27}$ también es cierto que tales órganos derivados pueden tener legitimación pasiva en la causa en caso de que sean autónomos de los órganos primarios, cuando éstos sean demandados. ${ }^{28}$

Con base en este criterio, la Suprema Corte de Justicia de la Nación ha sostenido que los secretarios de Estado, aunque no se encuentren previstos

25 Arteaga Nava, Elisur, La controversia constitucional, la acción de inconstitucionalidad y la facultad investigadora de la Corte: el caso Tabasco y otros, 3a. ed., México, Monte Alto, 1997, p. 19.

26 Tesis aislada 2a. LXXXVIII/98, "CONTROVERSIAS CONSTITUCIONALES. UN ORGANISMO PÚBLICO DESCENTRALIZADO ESTATAL CARECE DE LEGITIMACIÓN ACTIVA EN LA CAUSA", Semanario Judicial de la Federación y su Gaceta, Novena Época, t. VII, junio de 1998, p. 421, registro: 903,862.

27 Tesis aislada P. LXXIII/98, "CONTROVERSIA CONSTITUCIONAL. LEGITIMACIÓN ACtiva y Legitimación PASIVA", Semanario Judicial de la Federación y su Gaceta, Novena Época, t. VIII, diciembre de 1998, p. 790, registro 195,024.

28 Tesis de jurisprudencia P./J. 84/2000, “LEGITIMACIÓN PASIVA EN CONTROVERSIAS CONSTITUCIONALES. CARECEN DE ELla los ÓRgANOS SUBORDinAdos", Semanario Judicial de la Federación y su Gaceta, Novena Época, t. XII, agosto de 2000, p. 967, registro 191,294). 
en el artículo 105, fracción I de la Constitución, tienen legitimación pasiva dentro de las controversias constitucionales, cuando hayan intervenido en el refrendo del decreto impugnado. ${ }^{29}$

También ha sostenido que la Comisión Federal de Competencia, aun cuando no es un órgano originario del Estado, sino derivado, tiene legitimación pasiva ad causam en las controversias constitucionales, en virtud de que, al ejercer sus atribuciones relativas a la prevención, investigación y combate de monopolios, prácticas monopólicas y concentraciones, lo hace con autonomía y plena potestad, inclusive para ejecutar sus determinaciones. ${ }^{30}$

El criterio original que sostenía que la fracción I del artículo 105 de la Constitución Política establecía "limitativamente los órganos, poderes o entidades legitimadas para promover la acción de controversia constitucional", se fue modificando progresivamente, sobre todo en la ejecutoria dictada el 4 de noviembre de 2003 por el Pleno de la Suprema Corte de Justicia de la Nación, dentro de la controversia constitucional 28/2002, promovida por la Delegación Benito Juárez del Distrito Federal, en la afirmó lo siguiente:

En este aspecto, cabe señalar que esta Suprema Corte de Justicia de la Nación ha sostenido que tratándose de las controversias constitucionales, el artículo 105, fracción I, de la Constitución Federal, no debe interpretarse en un sentido literal o limitativo, ni que establezca un listado taxativo de los supuestos que pueden dar lugar a plantear esa vía, sino que debe interpretarse en armonía con las normas que establecen el sistema federal y el principio de división de poderes, con la finalidad de que no queden marginados otros supuestos...

En la ejecutoria mencionada, el Pleno de la Suprema Corte de Justicia de la Nación consideró que las delegaciones del Distrito Federal tienen legitimación activa ad causam para promover controversias constitucionales, porque constituyen un nivel de gobierno, cuentan con patrimonio propio, tienen delimitado su ámbito de atribuciones competenciales en la ley por

29 Tesis de jurisprudencia P./J. 109/2001, “SECRETARIOS DE ESTADO. TIENEN LEGITIMACIÓN PASIVA EN LA CONTROVERSIA CONSTITUCIONAL CUANDO HAYAN INTERVENIDO EN EL REFRENDO DEL DECRETO IMPUGNADO" Semanario Judicial de la Federación y su Gaceta, Novena Época, t. XIV, septiembre de 2001, p. 1104, registro 188,738.

30 Tesis de jurisprudencia P./J. 10/2004, “COMISIÓN FEDERAL DE COMPETENCIA ECONÓMICA. TIENE LEGITIMACIÓN PASIVA EN CONTROVERSIA CONSTITUCIONAL, PUES EMITE RESOLUCIONES CON PLENA AUTONOMÍA", Semanario Judicial de la Federación y su Gaceta, Novena Época, t. XIX, marzo de 2004, p. 1056, registro 182,015. 
mandato constitucional y no guardan una total subordinación respecto al jefe de gobierno. ${ }^{31}$

\section{LOS ÓRGANOS CONSTITUCIONALES AUTÓNOMOS}

El proceso de creación de los órganos constitucionales autónomos se inició apenas un año antes de la reforma constitucional de 1994, pero se ha desarrollado y consolidado con posterioridad a dicho año.

En efecto, el Banco de México, que desde su fundación en 1925 había tenido la forma de una sociedad anónima y en 1983 se transformó en un organismo público descentralizado, adquirió el carácter de órgano autónomo en 1993, en virtud del decreto publicado en el Diario Oficial de la Federación del 20 de agosto de ese año, que adicionó los párrafos sexto y séptimo del artículo 28 de la Constitución Política. En tales párrafos se establece que el Estado tendrá un banco central que será autónomo en el ejercicio de sus funciones y en su administración; y cual regulará los cambios, así como la intermediación y los servicios financieros.

Si bien es cierto que Instituto Federal Electoral se creó desde 1990, no fue sino hasta 1996 cuando se convirtió en órgano autónomo, como consecuencia del decreto publicado en el Diario Oficial de la Federación el 22 de agosto de ese año, que reformó, entre otros, el artículo 41 de la Constitución Política. La fracción III de este precepto establece que la organización de las elecciones federales es una función estatal que se realiza a través del organismo público autónomo Instituto Federal Electoral, dotado de personalidad jurídica y patrimonio propios.

En 1990 se creó la Comisión Nacional de Derechos Humanos como órgano desconcentrado de la Secretaría de Gobernación. En 1992 se adicionó el apartado B al articulo 102 de la Constitución Política, en el cual se facultó al Congreso de la Unión y a las legislaturas de los Estados para establecer, en el ámbito de sus respectivas competencias, organismo públicos protectores de derechos humanos. Pero no fue sino hasta la reforma publicada el 13 de septiembre de 1999 cuando se previó que la Comisión Nacional de

31 Tesis de jurisprudencia P./J. 61/2003, "Controversias Constitucionales. Las delegaciones del Distrito Federal están legitimadas para promoverlas”, Semanario Judicial de la Federación y su Gaceta, Novena Época, t. XVIII, diciembre de 2003, p. 887, registro 182,683 . 
Derechos Humanos contará con autonomía de gestión y presupuestaria, personalidad jurídica y patrimonio propios (párrafo cuarto).

La característica esencial de estos órganos constitucionales autónomos es que son regulados por la Constitución Política como órganos autónomos del Estado, que no se encuentran subordinados a alguno de los tres poderes tradicionales. $^{32}$

En el texto reformado en 1994 del artículo 105, fracción I, de la Constitución Política sólo se previeron las controversias constitucionales entre las diversas entidades jurídicas que integran el Estado mexicano (Federación, estados, Distrito Federal y municipios), entre los poderes ejecutivo y legislativo en el ámbito federal y entre los poderes de las entidades federativas. Pero no se consideró la posibilidad de que los órganos constitucionales autónomos fueran parte en los procesos de controversias constitucionales, por la sencilla razón de que tales órganos autónomos no se habían configurado como tales en 1994. Apenas en 1993 había empezado a surgir el primero de ellos, y los demás se estructurarían y desarrollarían después de 1994.

Esta omisión del órgano reformador de la Constitución no significa que éste se propuso excluir deliberadamente a los órganos constitucionales autónomos dentro de las controversias constitucionales, sino simplemente que no los tomó en cuenta por no haber estado plenamente estructurados. Fue una omisión por imprevisión, pero no por exclusión.

Desde el punto de vista formal, la solución más adecuada para reconocer legitimación activa en la causa a los órganos constitucionales autónomos para promover controversias constitucionales, sería una reforma al artículo 105, fracción I, de la Constitución Política. Pero en tanto esa reforma no llegue, cabe cuestionar si la interpretación que la Suprema Corte de Justicia haga de este precepto constitucional puede reconocer esa legitimación activa en la causa a tales órganos, tomando en cuenta que, al igual que las diversas entidades y poderes que integran el Estado mexicano, los órganos autónomos requieren de procesos jurisdiccionales para defender el ámbito de las atribuciones que les otorga la Constitución Política.

El tema de los órganos constitucionales autónomos ya ha sido abordado por la Suprema Corte. Al resolver el 22 de mayo de 2006 la controversia

32 Cfr. Caballero Ochoa, José Luis, "Los órganos constitucionales autónomos: más allá de la división de poderes”, Jurídica, núm. 30, 2000, pp. 155-156, y Gil Rendón, Raymundo, “Qué son los órganos constitucionales autónomos?”, Derecho y cultura, núm. 2, invierno de 2000-2001, p. 11. 
constitucional 32/2005, interpuesta por el municipio de Guadalajara, Jalisco, el Pleno afirmó que, con motivo de la evolución del concepto de distribución del poder público, se han introducido en el sistema jurídico mexicano, a través de diversas reformas constitucionales, órganos autónomos cuya actuación no está sujeta ni atribuida a los depositarios constitucionales del poder público; y que a tales órganos autónomos se les han encargado funciones estatales específicas, con el fin de obtener una mayor especialización, agilización, control y transparencia para atender eficazmente las demandas sociales. Asimismo, señaló que, aún cuando no existe algún precepto constitucional que regule la existencia de tales órganos, éstos deben: $a$ ) estar establecidos y configurados directamente en la Constitución; $b$ ) mantener con los otros órganos del Estado relaciones de coordinación; $c$ ) contar con autonomía e independencia funcional y financiera; y $d$ ) atender funciones coyunturales del Estado que requieren ser eficazmente atendidas en beneficio de la sociedad. ${ }^{33}$

Conforme con esta evolución progresiva, en la sentencia dictada por el Pleno de la Suprema Corte de Justicia de la Nación el 7 de noviembre de 2006, dentro de la controversia constitucional 31/2006, promovida por el Tribunal Electoral del Distrito Federal, se señaló la evolución y características de los órganos constitucionales autónomos. Sobre tales órganos la sentencia expresó lo siguiente:

1. Surgen en Europa y su establecimiento se expandió por Asia y América, como resultado de una nueva concepción del poder, bajo una idea de equilibrio constitucional basada en los controles de poder, evolucionando con ello la teoría tradicional de la división de poderes, por lo que se dejó de concebir la organización del Estado derivada de los tres poderes tradicionales (Ejecutivo, Legislativo y Judicial), que sin perder su esencia, actualmente se habla de que dicho principio debe considerarse como una distribución de funciones o competencia para hacer más eficaz el desarrollo de las actividades encomendadas al Estado.

33 La sentencia dictada por el Pleno de la Suprema Corte de Justicia de la Nación el 22 de mayo de 2006, en la controversia constitucional 32/2005, fue publicada en el Semanario Judicial de la Federación y su Gaceta, Novena Época, t. XXIV, octubre de 2006. La parte referente a los órganos constitucionales autónomos se localiza en las pp. 959-960. La tesis de jurisprudencia P./J.12/2008 que recoge el criterio sostenido en la sentencia mencionada, se publicó con el rubro "ÓRGANOS CONSTITUCIONALES AUTÓNOMOS. SUS CARACTERÍSTICAS", Semanario Judicial de la Federación y su Gaceta, Novena Época, t. XXVII, febrero de 2008, p. 1871. 
2. Su creación se justificó por la necesidad de establecer órganos encaminados a la defensa de los derechos fundamentales y de lograr controlar la constitucionalidad de los actos de los depositarios del poder público.

3. Se establecieron en los textos constitucionales, dotándolos de garantías de actuación e independencia en su estructura orgánica para que alcancen los fines para los que fueron creados, es decir, para que ejerzan una función propia del Estado, que por su especialización e importancia social requería autonomía de los clásicos poderes del Estado.

4. En el caso de nuestro país, la creación de este tipo de órganos no altera o destruye la tradicional doctrina de la división de poderes, pues la circunstancia de que los referidos órganos guarden autonomía e independencia de los poderes primarios no significa que no formen parte del Estado mexicano, pues su misión principal radica en atender necesidades torales tanto del Estado como de la sociedad en general, conformándose como nuevos organismos que se encuentran a la par de los órganos tradicionales.

5. Las características esenciales de estos órganos son: $a$ ) deben estar establecidos y configurados directamente en la Constitución, $b$ ) deben mantener con los otros órganos del Estado relaciones de coordinación, $c$ ) deben contar con autonomía e independencia funcional y financiera, y $d$ ) deben atender funciones primarias u originarias del Estado que requieran ser eficazmente atendidas en beneficio de la sociedad. ${ }^{34}$

En la misma ejecutoria, el Tribunal Pleno reiteró que el artículo 105, fracción I, de la Constitución federal no establece un listado taxativo de los órganos de poder que pueden interponer las controversias constitucionales. Esta parte de la sentencia dice lo siguiente:

En este aspecto, cabe señalar que esta Suprema Corte de Justicia de la Nación ha sostenido que, tratándose de las controversias constitucionales, el artículo 105, fracción I, de la Constitución Federal, no debe interpretarse en un sentido literal o limitativo, ni que establezca un listado taxativo de los supuestos que pueden dar lugar a plantear esa vía, sino que debe interpretarse en armonía con las normas que establecen el sistema federal y el principio de división de poderes, con la finalidad de que no queden marginados otros supuestos.

34 Semanario Judicial de la Federación y su Gaceta, Novena Época, t. XXV, abril de 2007, pp. 1217-1218. Las características mencionadas quedaron expresadas en la tesis de jurisprudencia P./J. 20/2007, "Órganos constitucionales autónomos. Notas distintivas y características", Semanario Judicial de la Federación y su Gaceta, t. XXV, mayo de 2007, p. 1647, registro 172,456 . 
Así entonces, el catálogo establecido en la fracción I del artículo 105 constitucional no debe entenderse como limitativo, sino meramente enunciativo, de tal manera que su aplicación no se realice en forma estrictamente literal, sino que deben favorecerse hipótesis de procedencia que, aunque no esté previstas expresamente en el texto de ese numeral, sean acordes con la finalidad manifiesta de este medio de control constitucional, que es precisamente salvaguardar las esferas de competencia de los órganos y poderes cuya existencia se prevé en la Constitución Federal. ${ }^{35}$

En esta ejecutoria se señala que de no otorgarse al Tribunal Electoral del Distrito Federal la posibilidad de acudir a la vía de controversia constitucional

estaríamos dejando el ámbito de competencia del Tribunal Electoral, en su calidad de órgano de gobierno del Distrito Federal, desprotegido y vulnerable, situación que no es acorde con la finalidad de este medio de control constitucional, el cual, como ya dijimos, salvaguarda las esferas de competencia de los órganos y poderes cuya existencia se prevé en la Constitución Federal. ${ }^{36}$

Por estimar que el Tribunal Electoral del Distrito Federal cumple con todos los requisitos de los órganos constitucionales autónomos, el Pleno de la Suprema Corte de Justicia determinó reconocerle legitimación activa en la causa para promover controversias constitucionales. ${ }^{37}$

En el rubro de la tesis que se cita en la nota 38 se expresa que se reconoce legitimación al Tribunal Electoral del Distrito Federal "al ser un órgano de gobierno del Distrito Federal”, pero este Tribunal es sólo un órgano jurisdiccional y no un órgano de gobierno. Por el contrario, al final de la tesis el texto es muy claro: “....es evidente que el Tribunal Electoral del Distrito Federal, como órgano constitucional autónomo, cuenta con legitimación para promover las controversias constitucionales a que se refiere el inciso k) de la fracción I del artículo 105 constitucional”.

Por último, como consecuencia de la mencionada sentencia dictada el 7 de noviembre de 2006, dentro de la controversia constitucional 31/2006,

35 Semanario Judicial de la Federación y su Gaceta, Novena Época, t. XXV, abril de 2007, pp. 1219-1220

36 Idem.

37 Tesis de jurisprudencia P./J. 19/2007, “Tribunal Electoral Del Distrito FeDERAL. Al SER UN ÓRGANO DE GOBIERNO DEL DisTRITO FEDERAL TIENE LEGITIMACIÓN para PROMOVER CONTROVERSIA CONSTITUCIONAL", Semanario Judicial de la Federación y su Gaceta, t. XXV, mayo de 2007, p. 1651, registro: 172,288. 
estableció jurisprudencia en la que se afirma que el artículo 105, fracción I, de la Constitución Política:

no debe interpretarse en un sentido literal o limitativo ni que establezca un listado taxativo de los entes, poderes u órganos legitimados para promover controversias constitucionales, sino en armonía con las normas que disponen el sistema federal y el principio de división de poderes, con la finalidad de que no queden marginados otros supuestos; de ahí que la aplicación del artículo 105, fracción I, de la Constitución Política de los Estados Unidos Mexicanos, debe favorecer hipótesis de procedencia que, aunque no estén previstas expresamente en su texto, sean acordes con la finalidad manifiesta de ese medio de control constitucional, que es precisamente salvaguardar las esferas de competencia de los órganos y poderes cuya existencia prevé la Constitución Federal. ${ }^{38}$

En conclusión, se puede afirmar que, de acuerdo con las tesis de jurisprudencia sostenidas por el Pleno de la Suprema Corte de Justicia, las características esenciales que deben satisfacer los órganos del Estado para ser considerados órganos constitucionales autónomos son las siguientes:

a) ser órganos originarios previstos directamente en la Constitución Política;

b) mantener relaciones de coordinación con los otros órganos del Estado;

c) tener autonomía e independencia funcional y financiera;

d) tener a su cargo funciones primarias u originarias del Estado que requieran ser eficazmente atendidas en beneficio de la sociedad.

De las tesis de jurisprudencia en cuestión se puede deducir que las características esenciales mencionadas se requieren para que los órganos constitucionales autónomos tengan legitimación activa en la causa para promover controversias constitucionales, aunque no estén previstos expresamente en

38 Tesis de jurisprudencia P./J. 21/2007, “CONTROVERSIA CONSTITUCIONAL. LA FRACCIÓN I DEL ARTÍCULO 105 DE LA CONSTITUCIÓN POLÍTICA DE LOS ESTADOS UNIDOS MEXICANOS, QUE PREVÉ LOS ENTES, PODERES U ÓRGANOS LEGITIMADOS PARA PROMOVERLA, NO ES LIMITATIVA", Semanario Judicial de la Federación y su Gaceta, Novena Época, t. XXVI, diciembre de 2007, p. 1101, registro 170,808 
el artículo 105, fracción I, de la Constitución Política. De otra forma, ¿cuál fue el objeto de que en la sentencia de 7 de noviembre de 2007 se hiciera un estudio tan completo de la evolución de estos órganos constitucionales autónomos y de que se señalaran con tanta precisión las características esenciales que deben reunir tales órganos? Para reconocer legitimación activa en la causa Tribunal Electoral del Distrito Federal como "órgano de gobierno" del Distrito Federal, habría bastado con citar el inciso k de la fracción I del artículo 105 de la Constitución Política, aunque es claro que ese Tribunal no puede ser considerado "órgano de gobierno", pues no ejerce funciones de gobierno sino funciones estrictamente jurisdiccionales. La parte final de la tesis que se cita en la nota 37 es muy clara: “...es evidente que el Tribunal Electoral del Distrito Federal, como órgano constitucional autónomo, cuenta con legitimación para promover las controversias constitucionales...".

Sin embargo, se debe advertir que la Suprema Corte no ha sido congruente con las tesis de jurisprudencia establecidas sobre los órganos constitucionales autónomos, las cuales no ha modificado pero sí ha dejado de cumplir.

A finales de 2006, la Comisión Nacional de Derechos Humanos promovió la controversia constitucional con número de expediente 150/2006. En contra del auto que admitió la demanda, el consejero jurídico de la Presidencia interpuso recurso reclamación, del cual conoció la Segunda Sala, con el número 20/2007-PL. En contra de las tesis de jurisprudencia aprobadas por el Pleno de la Suprema Corte, particularmente de la P./J. 21/2007, en la que se afirma que el artículo 105, fracción I, de la Constitución Política

no debe interpretarse en un sentido literal o limitativo ni que establezca un listado taxativo de los entes, poderes u órganos legitimados para promover controversias constitucionales, sino en armonía con las normas que disponen el sistema federal y el principio de división de poderes, con la finalidad de que no queden marginados otros supuestos.

Y de la tesis de jurisprudencia P./J. 19/2007, en la que reconoce que "es evidente que el Tribunal Electoral del Distrito Federal, como órgano constitucional autónomo, cuenta con legitimación para promover las controversias constitucionales", la Segunda Sala sostuvo que "la Comisión Nacional de Derechos Humanos carece de legitimación para promover la controversia constitucional, por no ser uno de los entes, poderes u órganos señalados específicamente en la fracción I del artículo 105 de la Constitución Política", y que al Tribunal Electoral del Distrito Federal no le reconoció 
legitimación por ser órgano constitucional autónomo, sino por ser "órgano de gobierno" previsto en el inciso k de la citada fracción I del artículo 105 constitucional. La resolución fue aprobada por el voto de tres ministros con el voto en contra dos ministros.

A principios de 2007, el Instituto Federal Electoral promovió la controversia constitucional 11/2007. En contra del auto que admitió la demanda, el presidente de la Cámara de Diputados interpuso recurso reclamación, del cual conoció el Pleno con el número 58/2007-PL. En contra de las tesis de jurisprudencia aprobadas por el Pleno de la Suprema Corte que acabamos de citar, la resolución del Pleno sostuvo que el artículo 105, fracción I, inciso c, de la Constitución Política contiene una "cláusula cerrada" de órganos federales y del Distrito Federal que pueden promover las controversias constituciones, y que, a pesar de que el Instituto Federal Electoral tenga la naturaleza de un órgano constitucional autónomo, no se le debe reconocer legitimación activa en la causa para promover controversias constitucionales. La resolución del Pleno fue aprobada por el voto de seis ministros, con el voto en contra de cinco ministros, por lo que no es apta para crear o modificar jurisprudencia.

Con motivo de la controversia constitucional 61/2005, promovida por el Municipio de Torreón, Coahuila, el Pleno la Suprema Corte de Justicia reconoció que el Instituto Coahuilense de Acceso a la Información Pública, por ser un organismo público autónomo, tiene legitimación pasiva en las controversias constitucionales en las que se impugnen sus actos. ${ }^{39}$ Esta misma razón debería llevar a la conclusión de que también debe tener legitimación activa en la causa.

La Segunda Sala ha aplicado el mismo criterio que utilizó para negar al Instituto Federal Electoral la legitimación activa en la causa, a los Institutos Electorales de los Estados. ${ }^{40}$ Esta tesis tampoco es apta para crear o modificar jurisprudencia.

39 Tesis de jurisprudencia P./J. 52/2008, "INSTITUTO COAHUILENSE DE ACCESO A LA INFORMACIÓN PÚBLICA. TIENE LEGITIMACIÓN PASIVA EN LA CONTROVERSIA CONSTITUCIONAL, PUES EJERCE SUS ATRIBUCIONES CON PLENA AUTONOMÍA", Semanario Judicial de la Federación y su Gaceta, Novena Época, t. XXVII, Junio de 2008, p. 962, registro 169477.

40 Tesis aislada 2a. XXVIII/2010, "INSTITUTOS ESTATALES ELECTORALES. NO TIENEN LEGITIMACIÓN ACTIVA PARA PROMOVER CONTROVERSIA CONSTITUCIONAL”, Semanario Judicial de la Federación y su Gaceta, Novena Época, t. XXXI, Abril de 2010, p. 2252, registro 164,765 . 
Aunque estas últimas resoluciones no modifiquen las tesis de jurisprudencia a que se ha hecho referencia, constituyen una grave regresión en la actitud de algunos ministros hacia la solución de de las controversias constitucionales. La apertura que había mostrado la jurisprudencia para interpretar en forma sistemática y no gramatical o literal el artículo 105, fracción I, de la Constitución Política, permitía precisamente que los conflictos sobre las atribuciones constitucionales de los órganos autónomos pudieran ser conocidos y resueltos conforme a derecho por la Suprema Corte de Justicia, en su carácter de tribunal constitucional.

La interpretación gramatical, literal o cerrada por la que se ha inclinado la mayoría de los ministros significa negar a los órganos constitucionales autónomos la posibilidad de defender sus propias atribuciones constitucionales, y dejarlos en estado de indefensión contra aquellos actos de los demás órganos y poderes que invadan o desconozcan tales atribuciones. Significa también una renuncia expresa de la propia Suprema Corte a ejercer su papel de tribunal constitucional, como órgano encargado de la solución de los conflictos entre entidades, poderes y órganos constitucionales, respecto los límites de sus atribuciones previstas en la Constitución Política.

Por lo demás, el juicio de amparo resultaría notoriamente improcedente en estos casos, pues la defensa de las atribuciones constitucionales de los órganos autónomos, no la pueden ejercer éstos como particulares, sino necesariamente como lo que son, como órganos constitucionales autónomos.

\section{BIBLIOGRAFÍA}

ACUÑa MÉNDEZ, Francisco, La controversia constitucional en México, México, Porrúa, 2004.

ARriaga BeCERRA, Hugo Alberto, "La controversia constitucional”, Lex, Torreón, 3a. Época, año I, núm. 3, septiembre, 1995.

Arteaga NaVA, Elisur, La controversia constitucional, la acción de inconstitucionalidad y la facultad investigadora de la Corte; el caso Tabasco y otros, 3a. ed. México, Grupo Editorial Monte Alto, 1997.

CABAllero OCHOA, José Luis, "Los órganos constitucionales autónomos: más allá de la división de poderes”, Jurídica, núm. 30, 2000.

CAlAmandreI, Piero, Instituciones de derecho procesal civil según el nuevo Código, trad. Santiago Sentís Melenmdo, Buenos Aires, EJEA, 1973 , t. I. 
Calvo Nicolau, Enrique, Cossío Díaz, José Ramón, Galindo MonROY, Jorge A. et al., Reglamento de la Ley del Servicio Público de Energia Electrica; Controversia constitucional 22/2001, México, ThemisBarra Mexicana, Colegio de Abogados, 2003.

CAStro y CAStro, Juventino V., El artículo 105 constitucional, 4a. ed., México, Porrúa, 2001.

Chiovenda, Giuseppe, Principios de derecho procesal civil, trad. de José Casais y Santaló, Madrid, Reus, 1977, t. II

Cossío DíAz, José Ramón, La controversia constitucional, México, Porrúa, 2008.

Couture, Eduardo J., Vocabulario jurídico, Buenos Aires, Depalma, 1976

DÁvila ESCAREÑO, Ángel, "Impartición de justicia: controversia constitucional", Vínculo Jurídico, Zacatecas, núm. 52, octubre-diciembre de 2002.

FERRER MAC-GREgor, Eduardo (coord.), Derecho procesal constitucional, 3a. ed., México, Porrúa-Colegio de Secretarios de la Suprema Corte de Justicia de la Nación, 2003.

FiX-ZAmudio, Héctor, Estudio de la defensa de la Constitución en el ordenamiento mexicano, México, Porrúa, 2005.

Fromont, Michel, La justice constitutionnelle dans le monde, París, Da1loz, 1996.

Fuente RodRíGUEZ, Jesús de la, Tratado de derecho bancario y bursátil, 2a. ed., México, Porrúa, 1999.

García Belaúnde, Domingo y Fernández Segado, Francisco (coords.), La jurisdicción constitucional en Iberoamérica, Madrid, Dykinson, 1997.

GARCÍA DE ENTERRÍA, Eduardo, La Constitución como norma y el Tribunal Constitucional, 3a. ed., Madrid, Civitas, 1998.

GARCÍA RAMírez, Sergio, "Constitucionalidad de leyes y actos de autoridad", Boletín Mexicano de Derecho Comparado, núm. 84, septiembrediciembre de 1995.

GIL RENDÓN, Raymundo, “¿Qué son los órganos constitucionales autónomos?", Derecho y Cultura, núm. 2, invierno de 2000-2001.

GonzÁlez-Trevijano SÁnchez, El Tribunal Constitucional, Madrid, Aranzadi, 2000.

GudiÑo PELAYO, José de Jesús, "La improcedencia y el sobreseimiento en la controversia constitucional”, Lex, Torreón, 3a. Época, año VI, núm. 
64, octubre de 2000.

HuERTA OCHOA, Carla, "El control de la constitucionalidad, análisis del artículo 105 constitucional”, Boletín Mexicano de Derecho Comparado, núm. 93, septiembre-diciembre de 1998.

LA PÉRGOLA, Antonio, "Funciones del tribunal constitucional en la democracia moderna", Externado, Bogotá, vol. 5, núm. 2, julio-diciembre de 1991.

MARCOU, Jean, Justice constitutionnelle et systèmes politiques. EtatsUnis, Europe, France, Presses Universitaires de Grenoble, 1997.

Melgar Adalid, Mario, "Hacia un auténtico tribunal constitucional", en Cuestiones constitucionales, México, núm. 11, julio-diciembre de 2004.

Moreira CARdoso DA Costa, José Manuel, "Tópicos sobre competencias e integración del Tribunal Constitucional de Portugal", Ius et praxis. Derecho en la región, Talca, Chile, año 8, núm. 1, 2002.

Orozco Gómez, Miguel, Procedimientos constitucionales: controversia constitucional y acción de inconstitucionalidad, México, Porrúa, 2004.

Ovalle Favela, José, Teoría general del proceso, 6a. ed., México, Oxford University Press, 2005.

PÉREZ RoYO, Javier, Tribunal constitucional y división de poderes, Madrid, Tecnos, 1988.

PODER JUdiCIAL DE LA FEDERACIÓN, ¿Qué son las controversias constitucionales? México, 2001.

RoBles Osollo, Ana Gloria, "La controversia constitucional como control de la constitucionalidad", Pemex Lex, núms. 101-102, noviembrediciembre, 1996.

Roussillon, Henry, Le Conseil Constitutionnel, 4a. ed., París, Dalloz, 2001.

RUgGeri, Antonio y SPADARO, Antonino, Lineamienti di giustizia costituzionale, Turín, Giappichelli, 2001.

Ruiz TORRes, Humberto Enrique, Derecho bancario, México, Oxford University Press, 2003.

SÁNCHEZ GIL, Rubén, "Resolución de 'cuestiones políticas': controversia constitucional y procedimiento senatorial", Revista Iberoamericana de Derecho Procesal Constitucional, México, núm. 8, julio-septiembre de 2007.

SEPÚlVEDA I., Ricardo J., "Reflexiones sobre la controversia constitucional (hacia un tribunal constitucional)", Revista de Investigaciones Juri- 
dicas, México, año 23, núm. 23, 1999.

SERNA DE LA GARZA, José María, "Controversias constitucionales. Concepto de fuero", Anuario Jurídico, México, 1996.

Tena Ramírez, Felipe, Leyes Fundamentales de México, 22a. ed, Porrúa, México, 1999.

TOMÁs y VALIENTE, Francisco, Escritos sobre y desde el Tribunal Constitucional, Madrid, Centro de Estudios Constitucionales, 1993.

TURRENT DíAz, Eduardo, Historia del Banco de México, vol. I, Banco de México, 1982.

Uribe ArZate, Enrique, El Tribunal Constitucional, México, Editorial Cigome, 2002.

ZAGREBELSKY, Gustavo, La giustizia costituzionale, 2a. ed., Bolonia, Il Mulino, 1988.

ZARCO, Francisco, Historia del Congreso Extraordinario Constituyente (1856-1857), El Colegio de México, México, 1856.

—Crónica del Congreso Extraordinario Constituyente (1856-1857), El Colegio de México, México, 1957.

ZAVALA RAZO, Jorge, "Las controversias constitucionales y las acciones de inconstitucionalidad", Indetec, Guadalajara, núm. 136, octubre de 2003. 